\title{
Demand Deficiency and Inflation in the G7 Countries
}

\author{
Erdem Başçı and Sıdıka Başçı̀̀
}

\begin{abstract}
In this paper, we analyze the relationship between nominal and real GDP growth for $\mathrm{G} 7$ countries for the period 1971 - 2018. A visual inspection of the data indicates the presence of a threshold, above which the structure of the relationship between nominal and real GDP growth rates changes from a positive one to a flat one. Moreover, the volatility of real growth is observed to be higher at high rates of nominal GDP growth. We first test for the presence of a two regime non-linearity by using the Sup F test of Andrews (1993). Due to the presence of heteroskedasticity we also apply the Sup MZ test of Ahmed et al. (2017). Both tests operate under an unknown change point and the latter also allows for heteroskedasticity. The results of the tests point to the presence of a 'demand deficiency 'regime for low nominal demand growth rates and to a 'harmful inflation 'regime for higher nominal GDP growth rates, these results have strong implications for guiding recent policy discussions on nominal GDP targeting.
\end{abstract}

\section{Key Words: Growth, Inflation, Macroeconomic Policy, Unknown Structural Change Tests, Nominal GDP Targeting}

JEL Codes : E01, E12, E31, C52

\section{INTRODUCTION}

Macroeconomic research over the last century has taught us two lessons. Lesson one is that too much growth in monetary spending is not good. ${ }^{1}$ Lesson two is that too little growth in monetary spending is also bad. ${ }^{2}$ In this paper we seek to quantify the range of ideal growth rates for nominal monetary spending, measured by nominal GDP growth, in G7 countries.

Our strategy is empirical. We utilize recently developed methods to test for the presence of two regimes on recent six decades of macroeconomic growth data from seven developed (G7) countries. The first regime is one of demand deficiency (DD). In this regime an effort to stimulate the nominal expenditure, measured by nominal GDP, pays off via a significant increase in real production, measured by real GDP.

The second regime is one of harmful inflation (HI). In this regime any effort to increase nominal expenditure is harmful, since it leads to higher inflation and the extra volatility in production that comes with it.

\footnotetext{
ò Erdem Başcı TED University, Department of Economics, Ankara, Turkey (email: erdem.basci@tedu.edu.tr) Sıdıka Başçı Ankara Yıldırım Beyazıt University, Department of Economics, Ankara, Turkey (email: sbasci@ybu.edu.tr). The authors are grateful İbrahim Ünalmış, Nergiz Dinçer, Jülide Yıldırım, to seminar participants at TED University, participants to the $20^{\text {th }}$ Syposium on Econometrics, Operations Research and Statistics and an anonymous referee of this Journal for useful comments. The usual disclaimer applies.

${ }^{1}$ See for example Fischer (1993).

${ }^{2}$ See for example Frankel (1995).
} 
By utilizing a two variable empirical strategy, we test for and estimate the two regions for the two regimes in question. We thereby are able to provide an idea to policy makers on the ideal range of nominal GDP growth. This empirical approach aims to provide a quantitative support to the newly emerging literature in nominal GDP targeting (Frankel, 1995, 2013, 2014; Chen, 2020).

\section{DATA AND MOTIVATION}

Real annual GDP growth rate and nominal annual GDP level data for the period $1971-2018$ for G7 countries are downloaded from World Bank database ${ }^{3}$. Nominal GDP growth rate is calculated by the authors as differences of natural logarithms. There are 336 observations for the whole G7 countries and 48 observations for individual countries. The time series graphs of the two variables are presented in the Annex 1.

For motivating the discussion, we plot the time series of this data for Italy in Figure 1 below. The case of Italy is interesting because she was hit by a double dip recession, in year 2009 and 2011, following the global financial crisis.

The cross-sectional plot of nominal and real growth rates of Italy is quite remarkable. In Figure 2 plots the same data in this fashion together with a 45 degrees line, which represents zero inflation of the GDP deflator.

Figure 1. From High Inflation to Demand Deficiency - The case of Italy

Nominal and Real GDP Growth for Italy

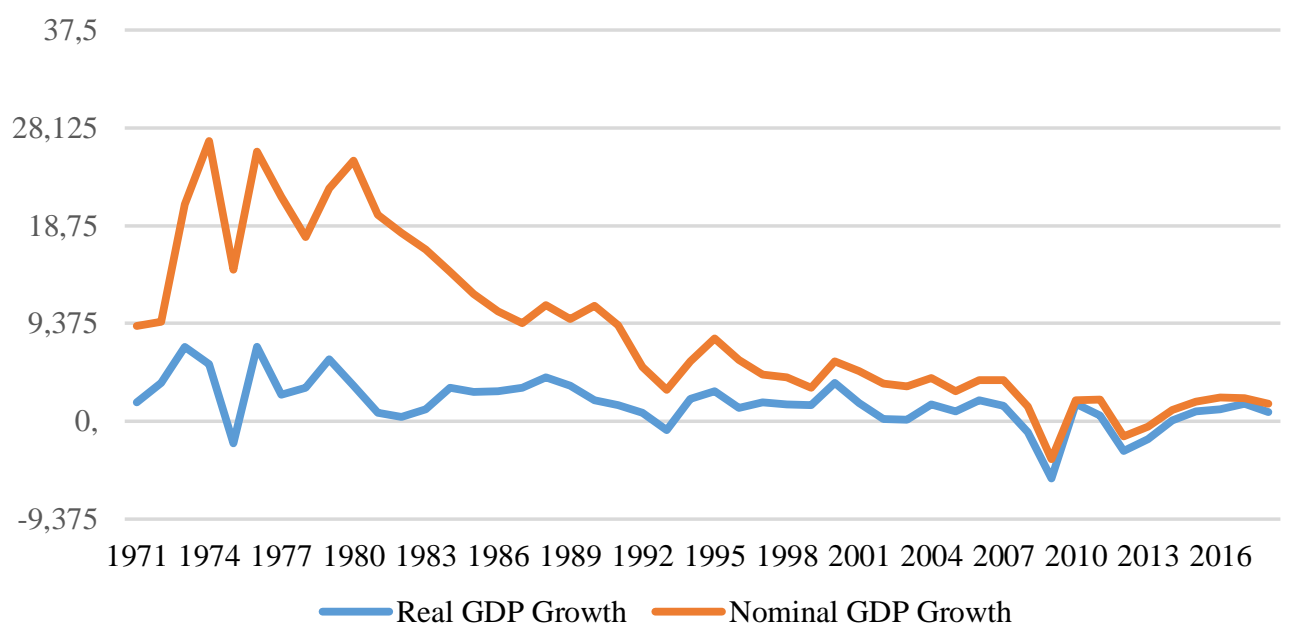

A visual inspection of the cross-section data leads us to the following observations:

- For values of nominal GDP growth below 5\%, the real GDP growth is suppressed to below potential.

- This points to the presence of a downward price rigidity. If prices cannot fall, output does.

- Yet, for values of nominal GDP growth above 5\%, the real GDP growth fluctuates around potential.

- This indicates the presence of upward price flexibility. If output cannot rise, prices do.

\footnotetext{
${ }^{3}$ https://data.worldbank.org/indicator
} 
In other words, we have evidence of both Keynesian and classical predictions on the same graph. For high nominal expenditure growth rates data behaves in line with the classical model's predictions. Yet for low levels of nominal expenditure growth, we are in a Keynesian region.

Therefore, the threshold level of the nominal GDP growth in transition from the Keynesian to a classical regime bears utmost importance. In order to estimate that threshold we utilize two econometric methods as described in Section 3 below.

Since both of these methods use asymptotic theory for their critical values, we use the pooled data for the whole 336 observations. The cross section of this data for all G7 countries for the sample period is plotted below in Figure 3.

Figure 2. Real versus Nominal GDP Growth - The case of Italy

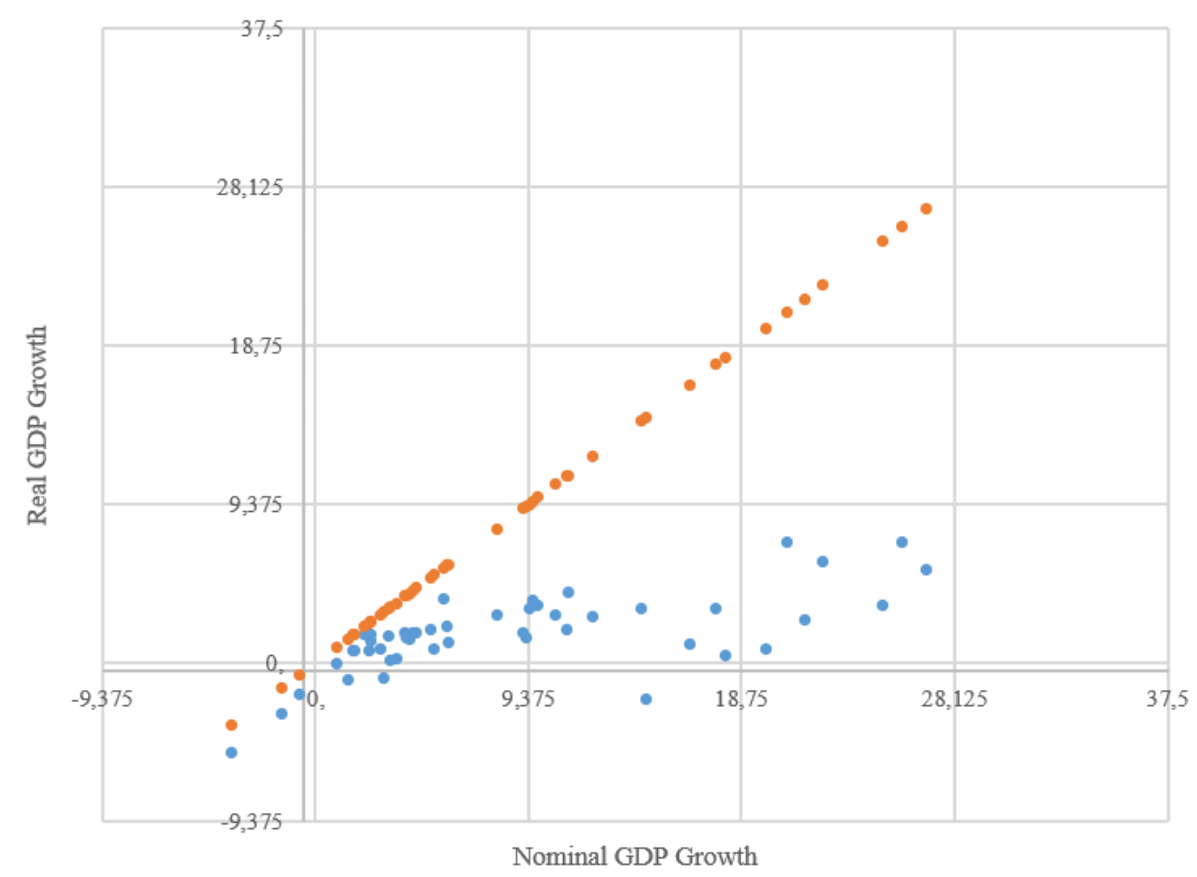


Figure 3. Nominal versus Real GDP Growth

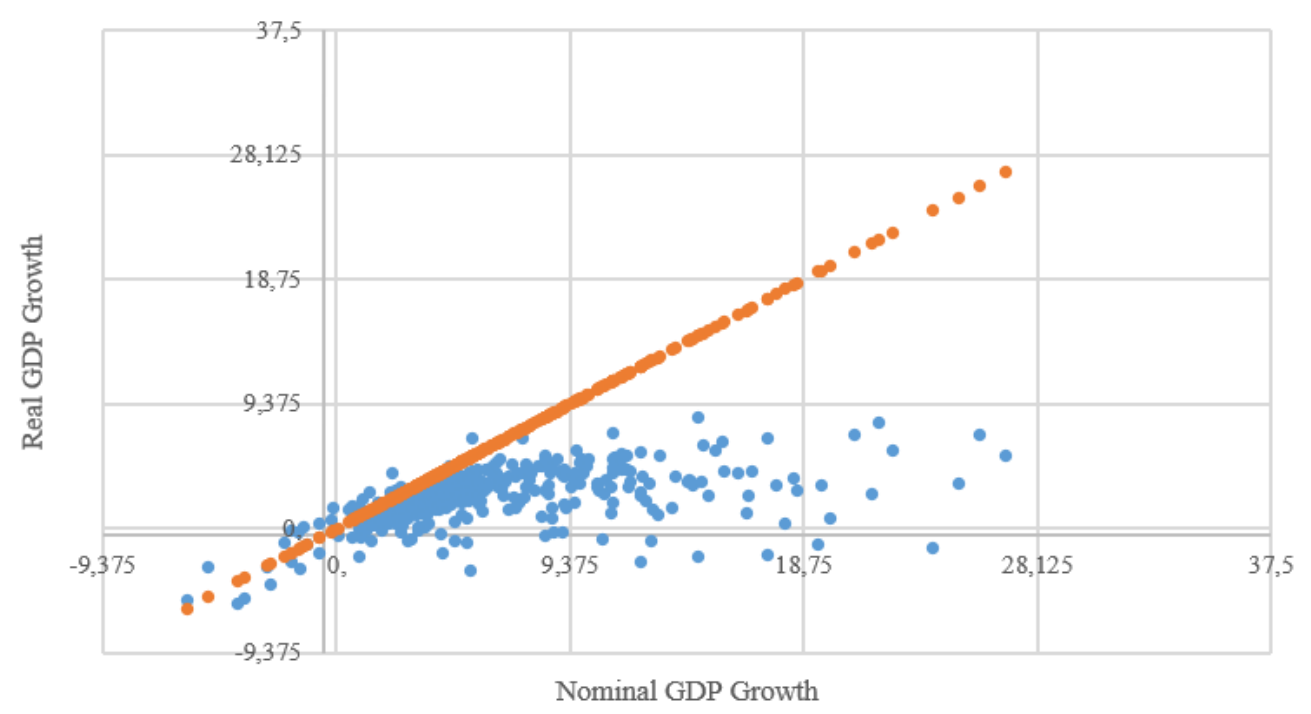

This figure is striking since the structural change can be noticed even by the naked eye. There seems to be two regimes, Keynesian and classical. Moreover, the exciting new research in econometric methods can help us identify the switching point between the two regimes.

For completeness of the visual inspection, Annex 2 presents the individual county data plotted in cross sections.

\section{ECONOMETRIC METHODOLOGY}

We will first test for the presence of a two regime non-linearity on the data of Figure 3 by using the Sup F test of Andrews (1993). Here, the test statistic is

$$
\operatorname{SupF}=\sup _{k \leq t^{*} \leq T-k} F_{t^{*}} \quad t^{*} \in\{1,2, \ldots, T-1\}
$$

This has been developed for the homoscedastic case.

Since by inspection we notice some heterogeneity in both Figures 2 and 3, we will also use the Sup MZ test of Ahmed et al. (2017). In this case, the test statistic is a likelihood ratio given by:

$$
\begin{gathered}
M Z=(T-k) \log \hat{\boldsymbol{\sigma}}_{0}^{2}-\left\{\left(T_{1}-k\right) \log \hat{\boldsymbol{\sigma}}_{1}^{2}+\left(T_{2}-k\right) \log \hat{\boldsymbol{\sigma}}_{2}^{2}\right\} \\
\text { SupMZ }=\sup _{k \leq t^{*} \leq T-k} M Z_{t^{*}} t^{*} \in\{1,2, \ldots, T-1\} .
\end{gathered}
$$

The later test for the presence of heteroskedasticity as well as different the OLS regression coefficients. Both of the tests operate with the assumption of an unknown change point over the domain.

This two regime non-linearity can be expressed by the standard linear regression model below.

$$
Y=X \beta+\epsilon, \epsilon i s i . i . d . N\left(0, \sigma^{2} I_{T}\right)
$$


where $Y$ is $T x l$ vector of independent variable, $X$ is $T x k$ matrix of regressors, $\beta$ is a $k x l$ vector of regression coefficients, and $\epsilon$ is a $T x l$ vector of regression errors. $\hat{\beta}_{0}=\left(X^{\prime} X\right)^{-1} X^{\prime} Y$ and $\hat{\sigma}_{0}^{2}=\left\|Y-X \hat{\beta}_{0}\right\|^{2} /(T-k)$ are the usual OLS estimates of the parameters $\beta$ and $\sigma^{2}$, respectively, under the null hypothesis of structural stability.

Let $\left(\beta_{i}, \sigma_{i}^{2}\right), i=1,2$ represent the $(k+1)$ parameters in each subgroup. The regression model for each subgroup is

$$
\begin{gathered}
Y_{1}=X_{1} \beta_{1}+\epsilon_{1}, \epsilon_{1} \text { isi.i.d.N }\left(0, \sigma_{1}^{2} I_{T_{1}}\right) \\
Y_{2}=X_{2} \beta_{2}+\epsilon_{2}, \epsilon_{2} \text { isi.i.d.N }\left(0, \sigma_{2}^{2} I_{T_{2}}\right)
\end{gathered}
$$

$\hat{\beta}_{i}=\left(X_{i}^{\prime} X_{i}\right)^{-1} X_{i}^{\prime} Y_{i}, i=1,2$ and $\hat{\sigma}_{i}^{2}=\left\|Y_{i}-X_{i} \beta_{i}\right\|^{2} /\left(T_{i}-k\right), i=1,2$ are the usual OLS estimates of the parameters for the two models, before and after the structural break. Specific to this paper the econometric model is

$$
g_{y}=\beta_{0}+\beta_{1} g_{Y}+\varepsilon
$$

where $g_{y}$ is real GDP growth, $g_{Y}$ is nominal GDP growth and $\varepsilon$ is the error term.

\section{RESULTS}

The regression equation has nominal GDP growth as its $\mathrm{x}$ axis. We therefore sort the data pairs in an increasing order according to the $\mathrm{x}$ axis variable.

Sup F test finds the break point at observation number 178 for the $\mathrm{G} 7$ pooled data presented in Figure 3. The corresponding nominal GDP rate at this break point is 5.36\%.

On the other hand, the estimated break point is at observation number 236 when Sup MZ test is used. Nominal GDP growth at this break point corresponds to $8.23 \%$.

Coming to the standard errors of regressions, they are 1.22 for observation up to 235 (i.e. a nominal growth of below $8.23 \%$ ) and 2.25 for the and for the rest of the observations. This clearly is in line with the presence of heteroscedasticity in the data. Real output growth volatility is higher when nominal expenditure growth is higher.

Since Sup MZ assumes simultaneous change in the regression coefficients and the variance at the change point, the estimated nominal GDP at the break point for Sup MZ turns out to be higher than that estimated by the Sup F test.

Now we are ready to check whether a regime change takes place at around and above 5.3 per cent nominal expenditure growth for each G7 country. The slope coefficient which is the sensitivity of real GDP growth to nominal growth is calculated for Regions 1 and 2 separately. 
Table 1 reports these estimated slope coefficients by OLS for each country. Region 1 can be identified as the demand deficiency (Keynesian) region. The slope coefficients for each of the G7 countries are positive and statistically very significant at one percent level.

In contrast, Region 2 can readily be identified as the harmful inflation (classical) region. The slope coefficients are much closer to zero and not significant at one percent level.

\begin{tabular}{|c|c|c|}
\hline & $\begin{array}{c}\text { Demand Deficiency Region } \\
\text { (Up to Observation 178) }\end{array}$ & $\begin{array}{c}\text { Classical Region } \\
\text { (After Observation 178) }\end{array}$ \\
\hline United States & 0.736 & 0.158 \\
$(4.25)$ & $(1.18)$ \\
\hline Japan & 0.721 & -0.005 \\
& $(9.53)$ & $0.04)$ \\
\hline Canada & 0.487 & $(0.26)$ \\
\hline \multirow{2}{*}{ United Kingdom } & $(3.19)$ & -0.097 \\
\hline Germany & 0.854 & $(-1.02)$ \\
\hline France & $(5.46)$ & 0.266 \\
& 0.744 & $(1.17)$ \\
\hline Italy & $(6.18)$ & 0.061 \\
& 0.725 & $(0.51)$ \\
\hline & $(9.57)$ & 0.124 \\
& 0.723 & $(2.08)$ \\
\hline
\end{tabular}

Table 1. Regression Coefficients, $\beta_{1}$, of the Equation (1) for the Two Regions Values in parenthesis are t-statistics.

\section{CONCLUSIONS}

In this paper we have observed and demonstrated that low levels of nominal expenditure growth may constrain real growth, while high values of nominal growth may lead to harmful inflation and volatility in growth.

This observation is consistent with the downward price rigidity (DPR) hypothesis. DPR becomes binding for values of nominal growth below a threshold.

We estimate this threshold of regime change by using two econometric methods developed for unknown change points.

The empirical results show clearly that the structure of the relationship between nominal and real GDP growth rates changes from a positive one to a flat one as GDP growth rates increase for all of the the G7 countries.

The positively sloped region is consistent with a 'demand deficiency' regime and the flat region is a typical classical 'potential growth' regime which is valid only for high nominal GDP growth rates. 
The volatility of real growth is higher at higher rates of nominal GDP growth. Demand deficiency becomes binding for values of nominal GDP growth below 5.4 percent. Above 8,2 per cent we gain nothing but additional volatility form further stimulus on nominal spending.

The findings support the case for nominal GDP targeting. Yet, in contrast to the nominal GDP level targeting suggested by Frankel (1995, 2013, 2014), Chen (2020), our findings would suggest a more practical GDP growth targeting. A target range between 5 and 8 per cent for nominal GDP growth would allow for real growth rates around potential of the G7 economies. Higher values of nominal GDP growth than 8 per cent would cause unnecessary volatility.

These observations are consistent with theories of price rigidity. The literature on macroeconomic implications of price rigidity based either on menu costs (Mankiw, 1985; Levy et al., 1997; Golosov and Lucas, 2007; Kehoe and Midrigan, 2015) or on discrete reference prices (Eichenbaum et al., 2011, Stevens, 2020) are consistent with high correlations of nominal and real GDP growth. Our results point however indicate that the downward price rigidity is more prominent.

As for future work, applying the methods of this paper for data of middle-income countries would be useful to test the idea coined by Frankel (2014) for these countries. ${ }^{4}$ Furthermore these results can also be compared to the results of the new literature on non-linear Phillips curves for developed countries. ${ }^{5}$

\section{REFERENCES}

Ahmed, M., G. Haider and A. Zaman (2017). Detecting structural change with heteroskedasticiy, Communications in Statistics-Theory and Methods, 46(21), 10446-10455.

Andrews, D.W. (1993). Tests for parameter instability and structural change with unknown change point, Econometrica, 61(4), 821-856.

Barro, R. J. (1991). Economic growth in a cross section of countries, The Quarterly Journal of Economics 106 (2), 407-443.

Bruno, M. and W. Easterly (1996). Inflation and Growth: In Search of a Stable Relationship, The Federal Reserve Bank of St. Louis Review, 78 (3), 139-146.

Chen, H. (2020). Nominal GDP targeting, real economic activity and inflation stabilization in a new Keynesian framework, The Quarterly Review of Economics and Finance, 78, 53-63.

Eichenbaum, M., N. Jaimovich and S. Rebelo (2011). Reference prices, costs, and nominal rigidities, American Economic Review, 101(1), 234-62.

Fischer, S. (1993). The Role of Macroeconomic Factors in Growth, Journal of Monetary Economics, 32(3), 485-512.

\footnotetext{
${ }^{4}$ Extremely high inflation rates can be observed for middle income countries. In such cases, in addition to higher volatility, potential real GDP growth rates are also affected negatively (e.g. Barro, 1991; Fischer, 1993; Bruno and Esterly, 1996 and Senoussi, 2021).

${ }^{5}$ See Forbes et al. (2021) and the related references therein.
} 
Forbes, K, J Gagnon and C Collins (2021). "Low Inflation Bends the Phillips Curve around the World: Extended Results", CEPR Discussion Paper 16583.

Frankel, J. (1995). The Stabilizing Properties of a Nominal GNP Rule, Journal of Money, Credit and Banking, 27(2), 318-334.

Frankel, J. (2013). "Nominal-GDP targets, without losing the inflation anchor," in Richard Baldwin \& Lucrezia Reichlin, eds., Is Inflation Targeting Dead: Central Banking After the Crisis (Centre for Economic Policy Research: London), 90-94.

Frankel, J. (2014). Nominal GDP Targeting for Middle-Income Countries, Central Bank Review, (Central Bank of the Republic of Turkey) 14(3), 1-14.

Golosov, M. and R. E. Lucas Jr (2007). Menu costs and Phillips curves, Journal of Political Economy, 115(2), 171-199.

Kehoe, P. and V. Midrigan (2015). Prices are sticky after all, Journal of Monetary Economics, $75,35-53$.

Levy, D., M. Bergen, S. Dutta and R. Venable (1997). The magnitude of menu costs: direct evidence from large US supermarket chains, The Quarterly Journal of Economics, 112(3), 791-824.

Mankiw, N.G. (1985). Small Menu Costs and Large Business Cycles: A Macroeconomic Model of Monopoly, The Quarterly Journal of Economics, 100(2), 529-538.

Senoussi, H. (2021). Variable Selection: An Application of the Random Forest Model to Barro Growth Regressions, International Econometric Review, 13(1), 4-23.

Stevens, L. (2020). Coarse pricing policies, The Review of Economic Studies, 87(1), 420-453. 
Annex 1. Real and Nominal GDP Growth for G7 Countries

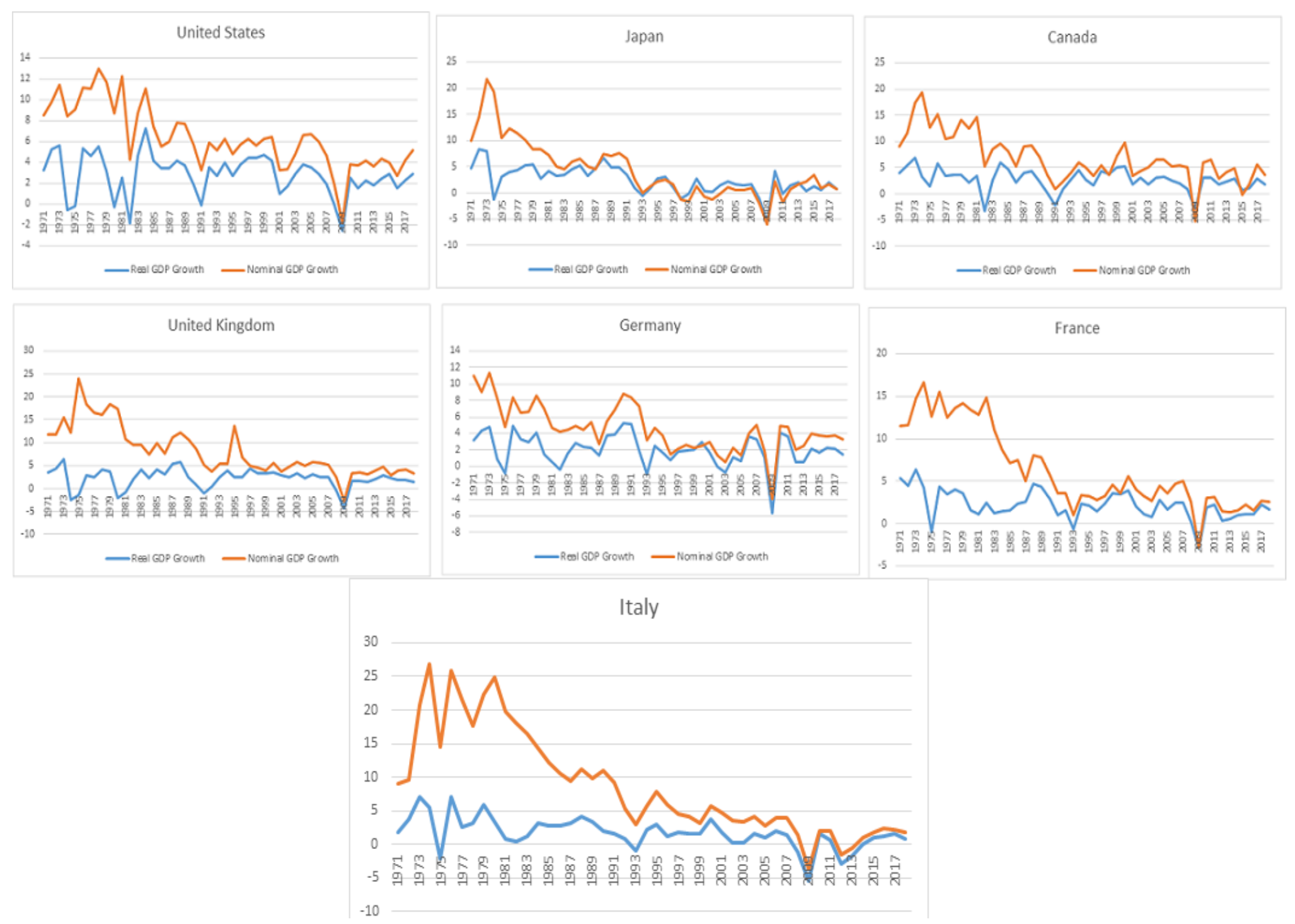




\section{Annex 2. Real versus Nominal GDP Growth for G7 Countries}
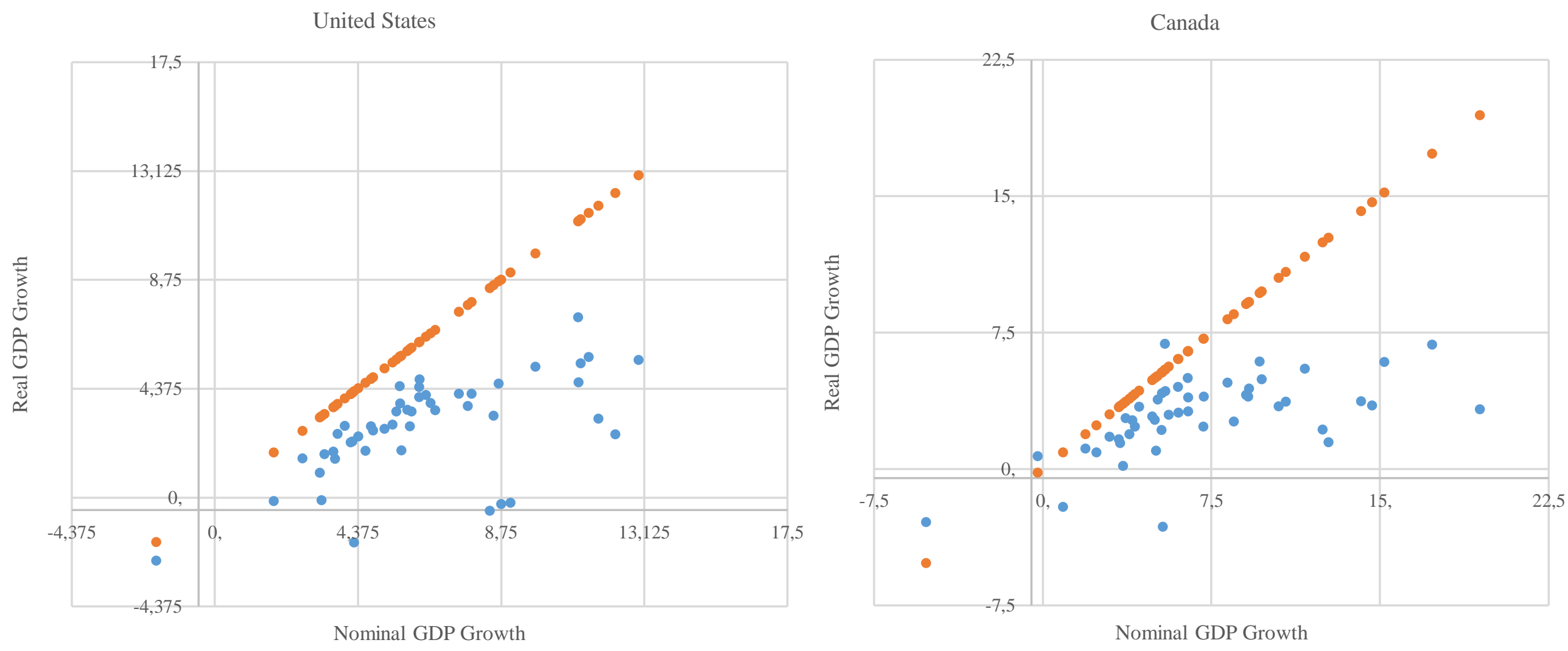

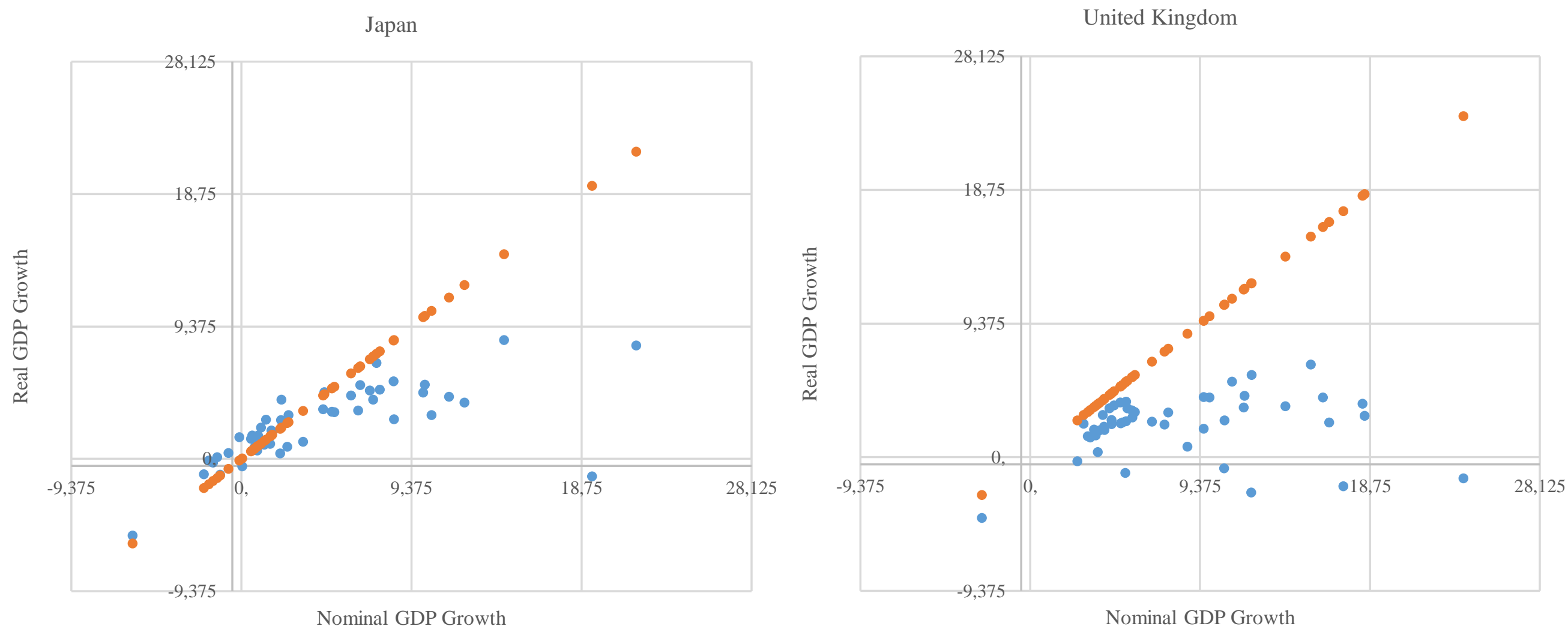


\section{Germany}

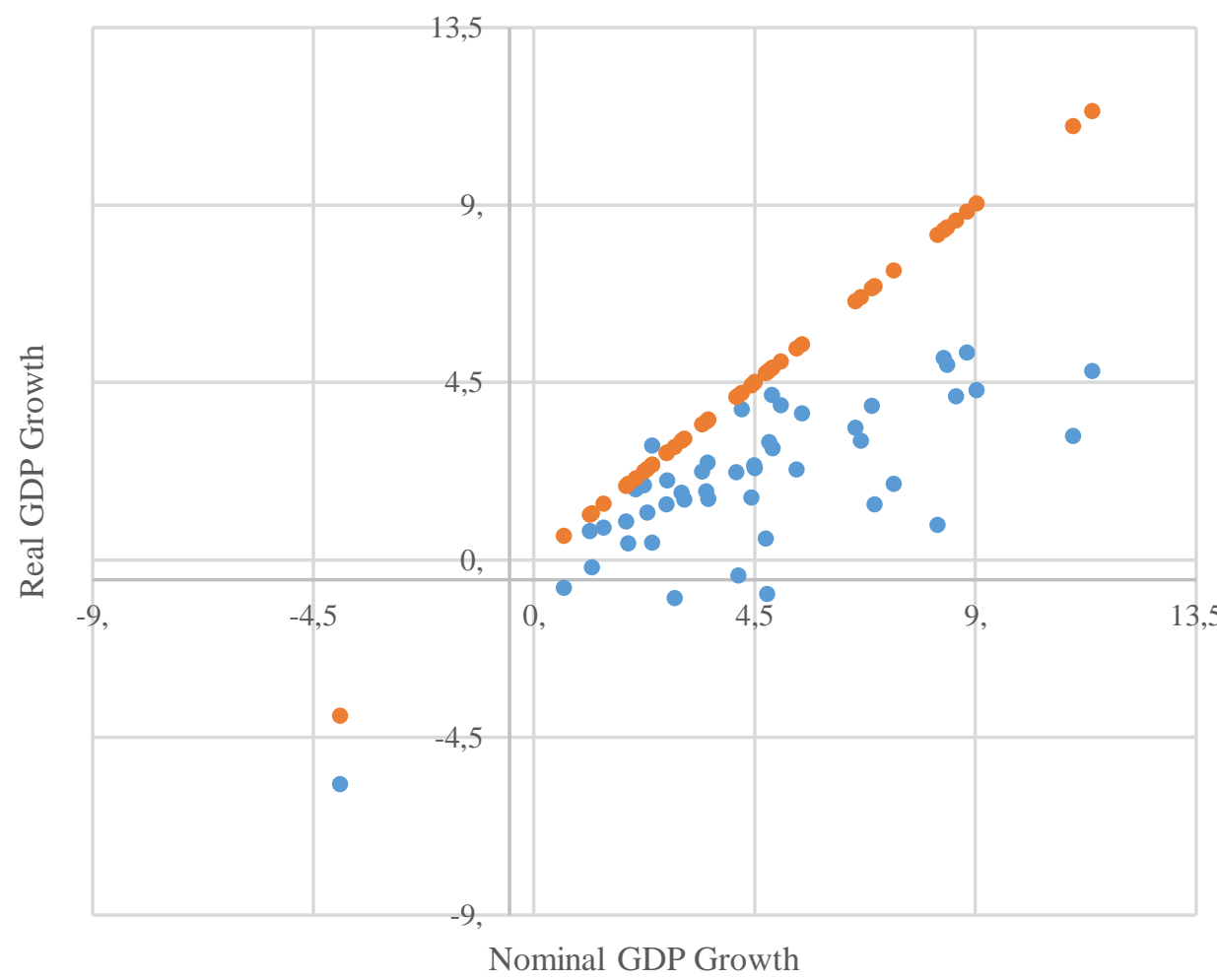

France

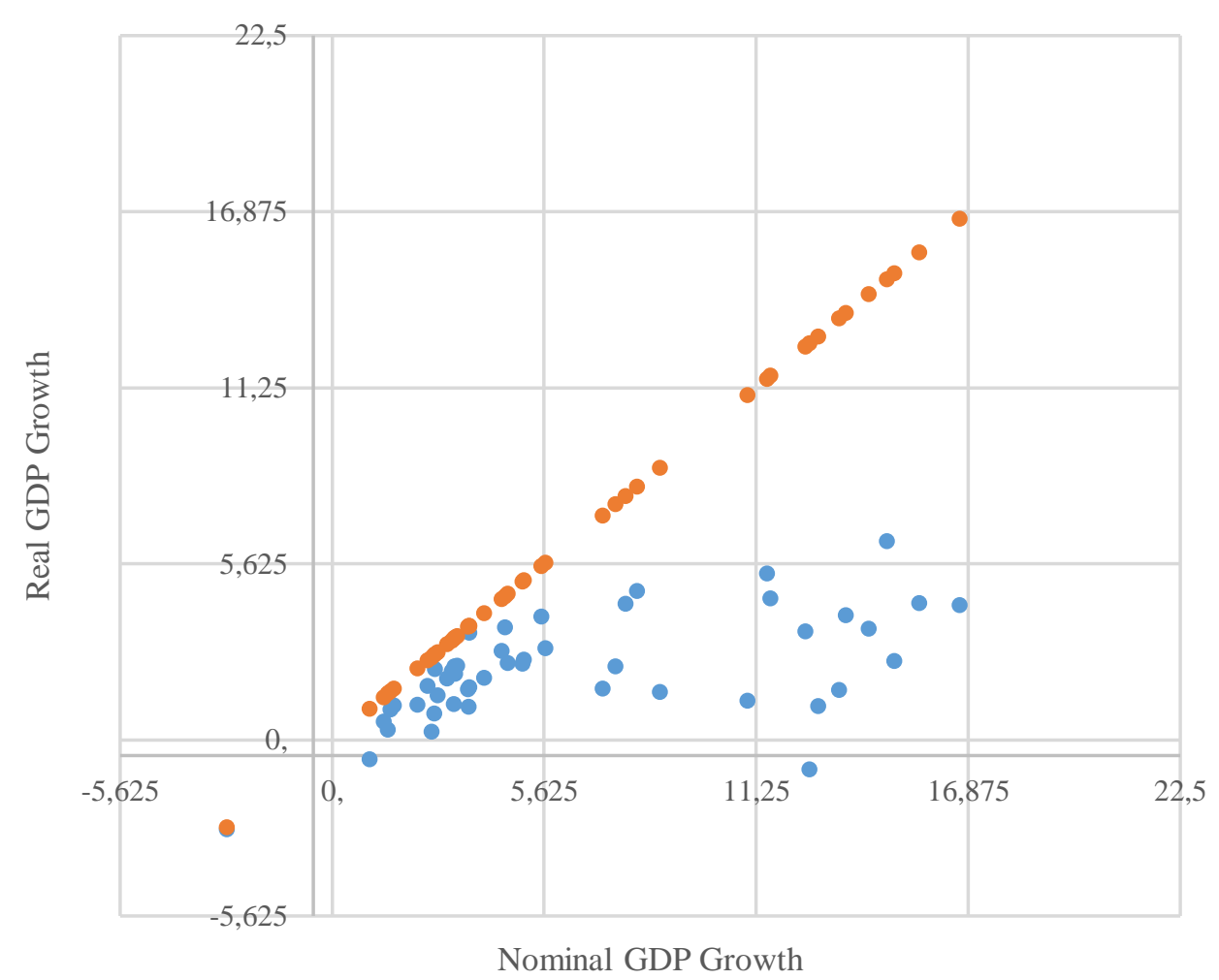

